\title{
Two cases of acute toluene intoxication
}

\author{
J Meulenbelt, G de Groot, T J F Savelkoul
}

\begin{abstract}
Two patients exposed to high concentrations of toluene in air $\left(>7000 \mathrm{mg} / \mathrm{m}^{3}\right)$ were found at the bottom of a small swimming pool under construction. Their symptoms were stupefaction, paresis, and amnesia. Patient $A$ had been exposed for three hours and patient $B$ for two hours. Ninety minutes after the exposure, the toluene blood concentration in patient $A$ was $4 \cdot 1 \mathrm{mg} / 1$ and in patient $B 2.2 \mathrm{mg} / 1$. Urinary ortho-cresol secretion was shown to be a good index of exposure to toluene. After high level exposure, urinary meta-cresol excretion may also be used to monitor toluene exposure.
\end{abstract}

Toluene is a widely used solvent and occupational exposure is common. A particular type of intoxication is caused by glue sniffing which, in some industrialised countries, has become a social problem. It is popular because toluene induces pleasant sensations, relaxation, and tranquility. Exposure to high concentrations resulting in severe toluene intoxication, except during sniffing, is observed infrequently and clinical and toxicological observations in cases of serious intoxications are scarce.

We describe two patients with severe, acute toluene intoxication. Special attention is paid to the metabolism of toluene in man and to the choice of reference parameters to monitor intoxication.

\section{Case histories}

Two men (aged 43 and 34) had tiled a small swimming pool $(6.0 \mathrm{~m}$ long, $0.90 \mathrm{~m}$ broad, and $2.5 \mathrm{~m}$ deep) to be used for exercise programmes in a rehabilitation clinic. Subsequently they had made the joints of cement between the tiles resistant to bleaching solutions with a special glue. The next day they removed the excess of glue from the tiles with toluene. Patient A started work at 0900 and patient B at 1000 . By coincidence, at 1215 both patients were found by their colleagues lying at the bottom of the pool.

National Poison Control Centre, National Institute of Public Health and Environmental Protection, 3720 BA, Bilthoven, The Netherlands

J Meulenbelt, G de Groot, T J F Savelkoul
The symptoms observed when they were found were stupefaction, paresis, and amnesia. They were lifted from the bottom of the pool and subsequently admitted to the University Hospital, Utrecht.

Both patients had previously been in good health. Physical examination was carried out one hour after they were found.

\section{PATIENT A}

Patient A had mucosal irritation of the eyes and slurred speech. He was stuporose and unable to walk or sit. Blood pressure was $140 / 70 \mathrm{~mm} \mathrm{Hg}$ and pulse 56 BPM. Auscultation of heart and lungs showed no abnormalities; on examination the abdomen was normal.

There were no haematological disorders. The concentration of serum creatinine was $78 \mu \mathrm{mol} / \mathrm{l}$, urea $7 \cdot 1 \mathrm{mmol} / 1$, sodium $141 \mathrm{mmol} / \mathrm{l}$, potassium 4.5 $\mathrm{mmol} / \mathrm{l}$, chloride $105 \mathrm{mmol} / \mathrm{l}$, and bicarbonate 24 $\mathrm{mmol} / \mathrm{l}$. Total bilirubin concentration, alkaline phosphatase activity, serum aspartate aminotransferase activity, and serum alanine aminotransferase activity were within the normal range. Blood gases, while room air was breathed, were $\mathrm{PaO}_{2} 71 \mathrm{~mm} \mathrm{Hg}$ and $\mathrm{PaCO}_{2} 41.9 \mathrm{~mm} \mathrm{Hg}$. Arterial $\mathrm{pH}$ was 7.39. The anion gap was $16.5 \mathrm{mmol} / 1$ (normal $<13 \mathrm{mmol} / \mathrm{l}$ ). Blood toluene concentration was $4 \cdot 1 \mathrm{mg} / \mathrm{l}$; the table shows the urinary ortho-, meta-, and para-cresol and phenol concentrations after exposure. The electrocardiogram showed a sinus bradycardia. The chest $x$ ray film was normal.

The amnesia lasted from about 1015 until 1330 . About four hours after being found, patient A experienced increasing pain in his right arm. Physical examination showed no fractures, contusions, or haematomas and the pain was probably caused by distortion of the elbow when he was lifted out from

Urinary excretion of some metabolites of toluene $(\mathrm{mg} / \mathrm{g}$ creatinine,

\begin{tabular}{crrll}
\hline & $o-C r e s o l$ & $m-C r e s o l$ & $p$-Cresol & phenol \\
\hline & \multicolumn{5}{c}{ Patient $A$} \\
$9-6 \mathrm{~h}$ & 10.7 & 2.62 & 52 & 3.57 \\
$6-18 \mathrm{~h}$ & 6.2 & 2.43 & 57 & 4.53 \\
$18-24 \mathrm{~h}$ & 12.4 & 1.77 & 38 & 3.68 \\
& & Patient B & & \\
$0-6 \mathrm{~h}$ & 6.9 & 2.29 & 50 & 2.29 \\
$6-18 \mathrm{~h}$ & 3.0 & 1.34 & 35 & 2.04 \\
$18-24 \mathrm{~h}$ & 10.5 & 2.57 & 56 & 3.57 \\
\hline
\end{tabular}


the pool. Presumably, the pain was not felt until after several hours because of the analgesic effect of the toluene. He was discharged from the hospital five hours after being found and his only complaint then was pain in his right elbow.

\section{PATIENT B}

Patient B had mucosal irritation of the eyes, was drowsy, and was just able to walk. He had normal speech and complained of headache. Blood pressure was $120 / 80 \mathrm{~mm} \mathrm{Hg}$, pulse rate $116 \mathrm{BPM}$. Auscultation of the heart showed a systolic murmur in the left parasternal, third intercostal space (grade I/VI). Auscultation of the lungs showed no abnormalities. On examination of the abdomen the liver was just palpable.

The haemaglobin concentration, platelets, and white cell counts were within the normal range. The concentration of serum creatinine was $76 \mu \mathrm{mol} / 1$, urea $4.4 \mathrm{mmol} / 1$, potassium $4.5 \mathrm{mmol} / 1$, sodium 140 $\mathrm{mmol} / \mathrm{l}$, chloride $106 \mathrm{mmol} / \mathrm{l}$, and bicarbonate $24 \cdot 2$ $\mathrm{mmol} / 1$. Total bilirubin concentration, alkaline phosphatase activity, serum aspartate aminotransferase activity, and serum alanine aminotransferase activity were within normal ranges. Blood gases, while room air was breathed, were: $\mathrm{PaO}_{2} 85 \mathrm{~mm} \mathrm{Hg}, \mathrm{PaCO}_{2} 39$ $\mathrm{mm} \mathrm{Hg}$. The arterial $\mathrm{pH}$ was $7 \cdot 40$. The anion gap was $14.3 \mathrm{mmol} / 1$. The blood toluene concentration was $2.2 \mathrm{mg} / \mathrm{l}$; the table shows the urinary $\mathrm{o}-, \mathrm{m}-$, and $\mathrm{p}-$ cresol, and phenol concentrations. The electrocardiogram showed a sinus tachycardia. The chest $x$ ray film was normal.

The duration of amnesia in this patient was from about 1015 to 1245 . He recovered within two hours and was discharged from the hospital in good health five hours after being found.

Both patients were investigated 24 hours and one week after the exposure. During this period no haematological disorders or renal and hepatic involvement were observed. In the first week after exposure the first patient sometimes had periods of slight pain in his right elbow but thereafter, he was free of complaints.

\section{Materials and methods}

The toluene concentration in blood was determined by capillary gas chromatography with flame ionisation detection. After the blood sample had been collected, the blood was put into a special head space vial of glass with a content of about $45 \mathrm{ml}$, closed with a rubber membrane with a Teflon lining, and stored at $4^{\circ} \mathrm{C}$. The vial may be stored for several days without loss of toluene. A gas tight syringe of $1000 \mu \mathrm{l}$ (Precision Sampling type Pressure Lok) was used for injection of head space air. From the head space air, an aliquot of $200 \mu \mathrm{l}$ was used for gas chromatographic analysis on a Carb Erba 4130 GC (Carb Erba
Strumentazione, Milan, Italy). Separation took place on a $26 \mathrm{~m}$ glass capillary column WCOT CP Sil $5 \mathrm{CB}$. (Chrompack, Middelburg, NL) with an intern diameter of $0.34 \mathrm{~mm}$ and a film thickness of $1.3 \mu \mathrm{ng}$ Hydrogen was used as carrier gas and was set at pressure of 1.8 bar. Column temperature w⿳⺈冂大 programmed from $40^{\circ} \mathrm{C}$ to $160^{\circ} \mathrm{C}$ at a rate of $20^{\circ} \mathrm{C}$ min. For quantifying the results, an external calibray tion curve was made by using head space analysis of calibration samples of 0.2 and $10 \mu \mathrm{l}$ of toluene dissolved in $1000 \mathrm{ml} \mathrm{H}_{2} \mathrm{O}$. This mixture wag vigorously shaken for 15 minutes. Next, the samples and the calibration samples were incubated at roores temperature for two hours. A sample without toluenz showed no detectable toluene concentration. The detection limit was $<10-50 \mu \mathrm{g} / \mathrm{l}$. Subsequently, the toluene concentration of the samples were deter mined and converted by using the calibration curve.

$\mathrm{O}-, \mathrm{m}-$, and $\mathrm{p}$-cresol and phenol were determineo in urine by gas chromatography with flame ionisation detection. The cresols and phenol were extracted from urine with liquid-liquid extraction after acidio hydrolysis. To $5 \mathrm{ml}$ of urine, $1 \mathrm{ml}$ of internal standart solution (800 mg 3,4-dimethylphenol per litre of water) and $1 \mathrm{ml}$ of concentrated hydrochloric acid were added. The urine sample was hydrolysed b $\$$ heating the mixture in a water bath of $70^{\circ} \mathrm{C}$ for two hours. After cooling down to room temperature, $1 \mathrm{~m}$ of isopropyl ether was added. The mixture was vigorously shaken for 15 minutes and subsequentl9 centrifuged. The supernatant isopropyl ether wa $\overrightarrow{\hat{S}}$ transferred into a sample vial and $2 \mu \mathrm{l}$ was used for $\bar{\nexists}$ gas chromatographic analysis. Separation was on borosilicate glass column (6 ft long, $2 \mathrm{~mm}$ internal. diameter) packed with 80/100 mesh Carbopack $\bigcirc$ coated with $0 \cdot 1 \%$ SP-1000 (Supelco). Helium (39 $\mathrm{ml} / \mathrm{min}$ ) was used as a carrier gas. Typical retentio times were of phenol 1.52 minutes, of $0-3.92$, of $\mathrm{m}^{2}$. $4 \cdot 54$, and of p-cresol $4 \cdot 88$, and of 3,4 dimethylpheno $17 \cdot 43$.

\section{Discussion}

The history in these cases was suggestive of exposur to toluene. The symptoms of stupefaction, paresis and amnesia were compatible with severe toluene intoxication and caused by severe depression of the central nervous system.

Solid evidence for toluene intoxication was proo vided by the blood toluene concentration. The bloo toluene concentration two hours after exposure was in patient $A 4.1 \mathrm{mg} / \mathrm{l}$ and in patient $\mathrm{B} 2.2 \mathrm{mg} / \mathrm{l}$. The blood toluene concentration is below the detection limits in unexposed individuals. Carlsson found, 96 minutes after the end of the exposure to toluene, $\overrightarrow{\mathrm{g}}$ blood toluene concentration of $18-30^{\circ}{ }_{0}$ of the con $\vec{D}$ centration at the end of the exposure. ${ }^{1}$ After a perio ${ }^{8}$ of 90 minutes, Veulemans found a toluene concentras tion around $30^{\circ}{ }^{\circ}$ of the concentration at the end $ळ$ 
the exposure; after 120 minutes, the concentration was $25^{\circ}{ }_{0}{ }^{2}$ The decrease of toluene concentration is most pronounced within the first few minutes, further decline occurs more gradually. ${ }^{23}$ From these data it may be concluded that the blood toluene concentration in both patients was much higher at the end of the exposure than that determined subsequently. Toluene blood concentrations in postmortem specimens of fatal cases have varied from 10 to $33 \mathrm{mg} / \mathrm{l}^{45}$

Hepatic and renal involvement was not noticed. The anion gap was slightly increased (in patient $A$ $16.5 \mathrm{mmol} / \mathrm{l}$ and in patient $B 14.3 \mathrm{mmol} / \mathrm{l}$ ) either from distal tubular acidosis or increased concentration of the metabolites of toluene. Fischman and Oster and Patel and Benjamin described distal tubular acidosis in patients who were exposed chronically to high concentrations of toluene. ${ }^{67}$ Fischman and Oster suggested that an increased anion gap could also be caused by an increased concentration of the metabolites of toluene such as benzoic acid or hippuric acid. Since the present patients were not chronically exposed to high toluene concentrations the anion gap seems to have been caused by an increase in the concentration of metabolites of toluene.

The high toluene concentration in the swimming pool provided evidence that both patients were seriously exposed to toluene. Three hours after the patients were rescued the toluene concentration was $>7000 \mathrm{mg} / \mathrm{m}^{3}$ (=1842 ppm) at the edge of the pool. A more precise calculation could not be made by the fire brigade because the concentration was determined by Dräger tubes. Since toluene is heavier than air it had probably sunk to the bottom of the pool where the concentration was presumably even higher.

The acute effects observed in man of a single, short term exposure to a toluene concentration of $1500 \mathrm{mg} /$ $\mathrm{m}^{3}$ are headache, dizziness, irritation of the throat and eyes, lachrimation, skin paraesthesia, incoordination, and mental confusion. With exposure to 3000 $\mathrm{mg} / \mathrm{m}^{3}$ the symptoms can be nausea, confusion, ataxia, amnesia, serious reduction in reaction time, and lack of self control. The effects after exposure to $15000 \mathrm{mg} / \mathrm{m}^{3}$ cause rapid impairment in reaction time and coordination. Exposure of one hour or more to this concentration may lead to narcosis and probably to death. ${ }^{8}$

Toluene is readily absorbed by inhalation and ingestion and rapidly metabolised by two oxidative routes. The major route is oxidation of the aliphatic chain. Approximately $80^{\circ}{ }_{0}$ of an absorbed dose is metabolised by this route with the formation of benzoic acid which is further conjugated either with glycine to hippuric acid, or with glucuronic acid to benzoyl glucuronic acid. The minor route is oxidation of the aromatic ring which potentially results in formation of o-, m-, and p-cresol. The cresols are excreted in urine as their corresponding glucuronide and sulphate conjugates. ${ }^{9}$

Since several food products contain benzoic acid, urinary hippuric acid excretion is related to intake of benzoic acid via the food. This causes a considerable, intraindividual variation. In a group of 39 unexposed individuals urinary hippuric acid excretion ranged between 0.086 and $2.340 \mathrm{~g} / \mathrm{g}$ creatinine (mean 0.739 $\mathrm{g} / \mathrm{g}$ creatinine).$^{10}$ On a group urinary hippuric acid excretion may be used to monitor exposure to toluene but on an individual basis it is an unambiguous index only after exposure to toluene concentrations above $3040 \mathrm{mg} / \mathrm{m}^{3}$ (=800 ppm). ${ }^{11}$ For similar reasons the excretion of benzoyl glucuronic acid is not a suitable index of toluene exposure.

Para-cresol is a normal constituent of urine of individuals not exposed to toluene. In 85 male human volunteers we determined the urinary para-cresol excretion and the results are shown in fig 1 . On the basis of these results, we calculated the reference values to be $3.3-63 \mathrm{mg} / \mathrm{g}$ creatinine. Obviously pcresol is not a suitable index of exposure to toluene either. For the same reason, urinary phenol excretion, which was determined in the same group of male healthy volunteers, is not an adequate indicator of exposure to benzene (fig 2); reference values for urinary phenol excretion were to be $0.8-16 \mathrm{mg} / \mathrm{g}$ creatinine.

In most published analytical procedures for determining cresols in urine, $\mathrm{m}$ - and $\mathrm{p}$-cresol are not separated. Our analytical procedure, however, was able to separate all three cresols. Therefore the excretion of $\mathrm{o}-$ and $\mathrm{m}$-cresol, which are not normal constituents of the urine, ${ }^{12}$ could be monitored as well. In the rat metabolites of toluene included o- and p-cresol but not m-cresol. ${ }^{13}$ In man it has been assumed that only o- and p-cresol are formed after exposure to toluene. ${ }^{1415} \mathrm{~A}$ linear relation between exposure to toluene and urinary o-cresol excretion

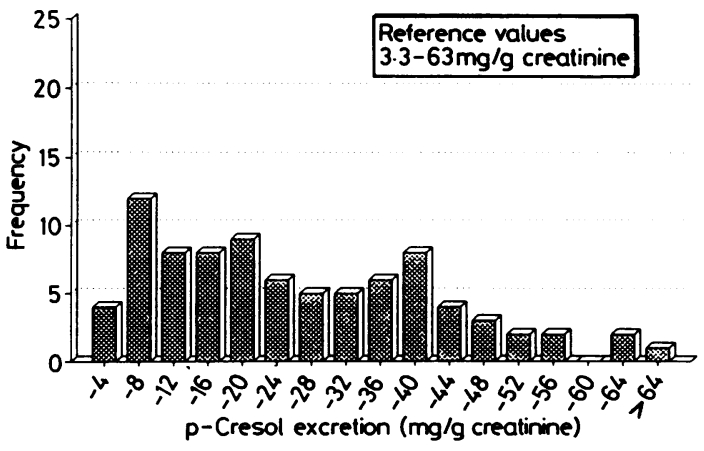

Figure 1 Frequency distribution of urinary p-cresol excretion in 85 male volunteers. Figures on concentration axis indicate upper limits of respective classes. Reference values were determined by a non-parametric method. 


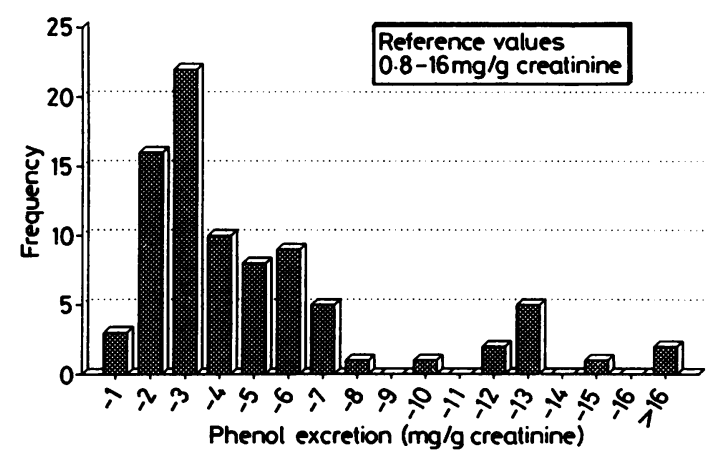

Figure 2 Frequency distribution of urinary phenol excretion in 85 male volunteers. Figures on concentration axis indicate upper limits of respective classes. Reference values were determined by a non-parametric method.

was observed up to a toluene concentration in air of $120 \mathrm{ppm} .{ }^{16}$ Therefore, 0 -cresol is a potentially useful means by which to monitor toluene exposure.

In both patients the urinary excretion of all three cresols was determined as were urinary phenol excretion (table). Since benzene exposure was not involved, the urinary phenol excretion may intraindividually indicate normal renal excretion. Both the urinary excretion of phenol and of p-cresol were within the respective calculated reference values. Pcresol excretion, therefore, cannot be used to monitor toluene exposure. As expected from the high toluene exposure, o-cresol was excreted in the urine. $M$ cresol was also found in concentrations $0 \cdot 15-0 \cdot 45$ times those of o-cresol. To our knowledge this has been observed only once before. ${ }^{17}$ Evidence exists that formation of $\mathrm{m}$-cresol from toluene is highly unlikely ${ }^{14}{ }^{15}$ but with high toluene exposure, as in the present cases, other metabolic pathways may be activated. From these results it seems that urinary ocresol excretion is a selective means by which to monitor toluene exposure even at low levels. In addition, high level toluene exposure may be assessed on the basis of the urinary $m$-cresol excretion. The presence of $m$-cresol in the urine of both patients was confirmed by gas chromatography-mass spectrometry. The cresols were separated on a capillary column (length $25 \mathrm{~m}$, internal diameter $0.23 \mathrm{~mm}$ ) coated with CP Wax 57 CB (Chrompack) using a quadrupole gas chromatograph-mass spectrometer? (Finnigan 4000) operated in electron impact mode. $\Rightarrow$ The presence of $\mathrm{m}$-cresol as well as o- and $\mathrm{p}$-cresol $\stackrel{\text { 年 }}{+}$ was confirmed in all urine samples.

We thank Mrs B C A Tepas for determining the $\frac{\bar{D}}{\bar{D}}$ cresols in urine and $\mathrm{Mr} \mathrm{E}$ van der Heeft and MrQ A P J M de Jong for the mass-spectrometric confirmations. We also thank Mr P Slingerland and $\mathrm{Mr}$ A K D Liem for determining the toluene. concentration in blood.

1 Carlsson A. Exposure to toluene. Scand J Work Environ Health 1982;8:43-55.

2 Veulemans H, Masschelein R. Experimental human exposure to $?$ toluene. I. Factors influencing the individual respiratory $A$ uptake and elimination. Int Arch Occup Environ Health ${ }_{\text {197 }}$
1978;42:91-103.

3 Veulemans H, Masschelein R. Experimental human exposure to $\nexists$ toluene. II. Toluene in venous blood during and after $\vec{V}$ exposure. Int Arch Occup Environ Health 1978;42:105-17.

4 Bonnichsen R, Maehly AC, Moeller M. Poisoning by volatile compounds. I. Aromatic hydrocarbons. J Forensic Sci 1966; 11:186-204.

5 Collom WD, Winek CL. Detection of glue constituents in fatalities due to "glue sniffing." Clin Toxicol 1970;3:125-30. จ

6 Fischman CM, Oster JR. Toxic effects of toluene. JAMA 1979;241:1713-5.

7 Patel R, Benjamin J. Renal disease associated with toluene inhalation. Clin Toxicol 1986;24:213-23.

8 World Health Organisation. Toluene. Geneva: WHO, 1985. (Environmental health criteria 52.)

9 Veulemans R. Bepalingen van metabolieten in urine als maat voor expositie aan benzeen, tolueen, xyleen en styreen. $\bar{D}$ Tijdschrift voor Sociale Geneeskunde 1976;54:666-76.

10 Engström K, Husman K, Rantanan J. Measurement of toluene $\varrho$

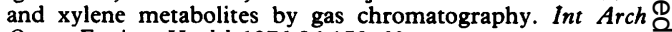
Occup Environ Health 1976;36:153-60.

11 Bakke OM, Scheline RR. Hydroxylation of aromatic hydrocarbons in the rat. Toxicol Appl Pharmacol 1970;16: 691-700.

12 Angerer J. Occupational chronic exposure to organic solvents, VII. Metabolism of toluene in man. Int Arch Occup Environ Health 1979;43:63-7.

13 Von Oettingen WF, Neal PA, Donahue DD. The toxicity and potential dangers of toluene: preliminary report. $J A M A$ 1942;118:579-84.

14 Daly JW, Jerina DM, Witkop B. Arene oxides and the NIH shift: the metabolism, toxicity and carcinogenicity of aromatic compounds. Experimentia 1972;28:1129-264.

15 Kaubisch N, Daly JW, Jerina DM. Arene oxides as intermediates in the oxidative metabolism of aromatic compounds. Isomerization of methyl-substituted arene oxides. Bio- $\mathrm{O}$ chemistry 1972;12:3080-8.

16 Pfäffli P, Savolainen H, Kalliomäki PL, Kalliokoski P. Urinary D 0 -cresol in toluene exposure. Scand $J$ Work Environ Health 1979;5:286-9.

17 Woiwode W, Wodarz R, Drysch K, Weichardt H. Metabolism N of toluene in man: gas-chromatographic determination of $0-$, , $\mathrm{m}$ - and p-cresol in urine. Arch Toxicol 1979;43:93-8.

Accepted 28 November 1989 